\title{
Warfarin Binding to Native and Structurally-Altered Human Serum Albumins
}

\author{
Nasim Sakhaei, Adyani Azizah Abdul Halim and Saad Tayyab* \\ Biomolecular Research Group, Biochemistry Programme, Institute of Biological Sciences, University of Malaya 50603 Kuala Lumpur, \\ MALAYSIA
}

\begin{abstract}
Background and Purpose: Interaction of a drug with the carrier protein in the circulation determines its distribution, free or bound concentration and metabolism. Structural alteration in the major transport protein, human serum albumin (HSA) under several pathological conditions may affect its drug binding ability. The objective of the present investigation was to explore the binding of warfarin to structurally-altered HSA. Methods: Effect of urea, a denaturant on the interaction of warfarin with HSA was investigated using fluorescence spectroscopy. Results and Discussion: Fluorescence spectra of native HSA were characterized by the presence of an emission maximum around 339 and $343 \mathrm{~nm}$, when excited at 280 and $295 \mathrm{~nm}$, respectively. Warfarin binding to HSA was marked by a significant decrease in the fluorescence intensity and red shift in the emission maximum, being more pronounced at lower (1-5 $\mu \mathrm{M})$ and smaller at higher (10-40 $\mu \mathrm{M})$ drug concentrations. Presence of urea affected these signals to a significant extent even at lower concentrations. A significant decrease in both quenching and binding constants with increasing urea concentrations, suggested separation of excited fluorophore (Trp) of HSA and warfarin leading to the loss in its drug binding ability.
\end{abstract}

Key words: Drug Binding, Fluorescence Quenching, Human Serum Albumin, Urea, Warfarin.

\section{INTRODUCTION}

Human serum albumin (HSA), the major transport protein of mammalian blood circulation binds a large number of drugs varying in structure. ${ }^{1}$ It is a single polypeptide chain with 585 amino acid residues, arranged in three structurally similar domains, I, II and III, which are comprised of two sub domains, A and B. ${ }^{2}$ Drug binding to HSA plays an important role in the pharmacokinetics of the drug by limiting the unbound concentration and affecting its administration and elimination. In some cases, the major fraction of the administered drug is determined by HSA. Structural studies have shown specific locations of these binding sites on $\mathrm{HSA}^{2}$. Many drugs bind to one of the two primary binding sites on the protein, known as Sudlow's sites I and II. ${ }^{3}$

Warfarin [3-( $\propto$-acetonylbenzyl)-4-hydroxycoumarin] is a widely used anticoagulant drug for the treatment of venous throm- bosis and pulmonary embolism, ${ }^{4,5}$ as well as in the prevention of prosthetic heart valve thromboembolism. ${ }^{6}$ Under normal therapeutic conditions, warfarin is $99 \%$ bound to the protein (HSA) in circulation and is therefore, known as a drug with small volume of distribution and low clearance. ${ }^{7}$ Warfarin is known to bind to site I of HSA, which is also known as the warfarin-azapropazone binding site. ${ }^{8,9}$ Due to its specific binding to site I on HSA, warfarin is often used as a competing agent or a marker ligand for investigating the specific binding of other drug molecules to site I on HSA. ${ }^{10-12}$

Denaturation usually results in the destruction of the protein's tertiary structure, leading to the change in its ligand binding ability since all functions of proteins are displayed by their three-dimensional structures. ${ }^{13}$ Under several pathological conditions, tertiary structure of HSA is altered. ${ }^{14}$ Such
Submission Date : 18-07-2014

Revision Date : :07-1-2015

Accepted Date : :5-2-2015

DOI: $10.5530 /$ ijper.49.3.8

Correspondence Address

Dr. Saad Tayyab

Biomolecular Research

Group,

Institute of Biological Sci-

ences,

University of Malaya 50603

Kuala Lumpur, MALAYSIA.

Email:saadtayyab2004@

yahoo.com

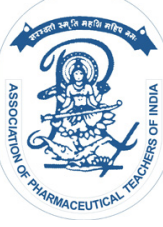

www.ijper.org 
structural alterations may affect ligand binding ability of HSA. In view of this, it would be of interest to study the binding of warfarin to structurally-altered HSA. Furthermore, for effective therapeutic monitoring of the drug, it is necessary to know the binding parameters of drug-protein interaction during HSA destabilization. In clinical situations, where plasma protein binding may be altered, total drug concentrations must be interpreted with caution..$^{15}$ Although, a number of reports are available in the literature on the binding of warfarin to $\mathrm{HSA}^{16-}$

${ }^{18}$ but no attempt has been made to study the effect of protein's structural alteration on the binding of warfarin to HSA. In view of the above, it would be of interest to study warfarin binding to HSA in the presence of different urea concentrations. Here, we present our data on the effect of urea on the warfarin binding to HSA.

\section{MATERIALS AND METHODS}

Human serum albumin, essentially fatty acid free (Lot 104K7636), warfarin (minimum 98\%) (Lot 104K1261) and ultra pure urea (Lot 127K01061) were purchased from Sigma-Aldrich Inc., USA. Other reagents used in this study were of analytical grade purity.

\section{Analytical methods}

Protein concentration was determined spectrophotometrically on a Shimadzu double beam Spectrophotometer; model IJV-2450, using a specific extinction coefficient, $\mathrm{E}_{279 \mathrm{~nm}}^{1 \%}$ of HSA as 5.31 . $^{2}$ The concentration of the stock urea solution was determined following the published procedure. ${ }^{19}$ The stock drug solution $(400 \mu \mathrm{M})$ was prepared by dissolving $3.1 \mathrm{mg}$ of warfarin in $25 \mathrm{ml}$ of $0.06 \mathrm{M}$ sodium phosphate buffer, $\mathrm{pH} 7.4$ with gentle heating at $37^{\circ} \mathrm{C}$.

\section{Fluorescence spectroscopy}

Fluorescence measurements were performed on a Hitachi Fluorescence Spectrophotometer, model F-2500. Fluorescence spectra were recorded at a protein concentration of $1.0 / 1.8 \mu \mathrm{M}$ with a $1-\mathrm{cm}$ path length cell. The excitation and emission slits were set at $10 \mathrm{~nm}$ each. Intrinsic fluorescence was measured by exciting the protein solution at either 280 or $295 \mathrm{~nm}$ and the emission spectra were recorded in the wavelength range, $300-400 \mathrm{~nm}$.

\section{Drug binding studies}

The interaction of warfarin with HSA was studied at different drug/protein molar ratios using fluorescence spectroscopy both in the absence and the presence of different urea concentrations. All experiments were carried out in $0.06 \mathrm{M}$ sodium phosphate buffer, $\mathrm{pH} 7.4$ at $25^{\circ} \mathrm{C}$.

Increasing volumes $(12.5-500 \mu \mathrm{l})$ of the stock drug solution $(400 \mu \mathrm{M})$ were added to a fixed volume $(280 \mu \mathrm{l} / 500$ $\mu \mathrm{l})$ of the stock protein solution $(18 \mu \mathrm{M})$, taken in different tubes and incubated for $20 \mathrm{~min}$ at $25^{\circ} \mathrm{C}$. It was followed by the addition of a fixed volume of the stock urea solution $(10 \mathrm{M})$. The final volume in each tube was made to $5 \mathrm{ml}$ with buffer, if required and the solution mixtures were incubated for additional $60 \mathrm{~min}$ at room temperature. Fluorescence spectra were recorded upon excitation at both 280 and $295 \mathrm{~nm}$. Same protocol was used in different experiments involving different urea concentrations. Drug-binding data were analyzed using Stern-Volmer equation. ${ }^{20}$

$$
F_{0} / F=1+K_{S V}[Q]
$$

Where $F_{0}$ and $F$ are the fluorescence intensities at an appropriate wavelength in the absence and the presence of drug, respectively, $K_{s v}$ is the Stern-Volmer constant and $[\mathrm{Q}]$ is the molar concentration of the drug.

Binding constant of drug-protein interaction was determined using following equation as suggested earlier. ${ }^{21}$

$$
\log \frac{F_{0}-F}{F}=\log K_{b}+\mathrm{n} \log [Q]
$$

Where $\mathrm{Q}$ is the drug concentration, $K_{b}$ is the binding constant, $\mathrm{n}$ is the number of binding sites and $F_{0}$ and $F$ are the values of fluorescence intensity in the absence and the presence of drug respectively. A plot of log $\left[\left(F_{0}-F\right) / F\right]$ versus $\log [\mathrm{Q}]$ yielded a straight line with a slope of $\mathrm{n}$ and y-axis intercept of $\log K_{b}$.

\section{RESULTS AND DISCUSSION}

Intrinsic fluorescence spectra of HSA $(1 \mu \mathrm{M})$ both in the absence and the presence of increasing warfarin concentrations $(1.0-40 \mu \mathrm{M})$, upon excitation at $280 \mathrm{~nm}$ are shown in Figure 1A. As can be seen from the figure, native HSA produced the fluorescence spectrum in the wavelength range, $300-400 \mathrm{~nm}$ with an emission maximum at $339 \mathrm{~nm}$. Appearance of an emission maximum at $339 \mathrm{~nm}$ can be ascribed to the presence of Trp residue in HSA. ${ }^{22,23}$ Presence of increasing warfarin concentrations in the incubation mixture led to a significant decrease in the fluorescence intensity and red shift in the emission maximum (Figure 1A). Presence of the emission maxima around $375 \mathrm{~nm}$ at higher warfarin concentrations may be attributed to the free warfarin fluorescence. Energy transfer from the protein fluorophores to warfarin in its ground state can account for the quenching observed in the protein fluorescence. This seems understandable in view of the significant overlap between the absorption spectrum of the drug (warfarin) and the emission spectrum of HSA (Figure not shown). Both decrease in the fluorescence intensity and red shift in the emission maximum of HSA with increasing war- 


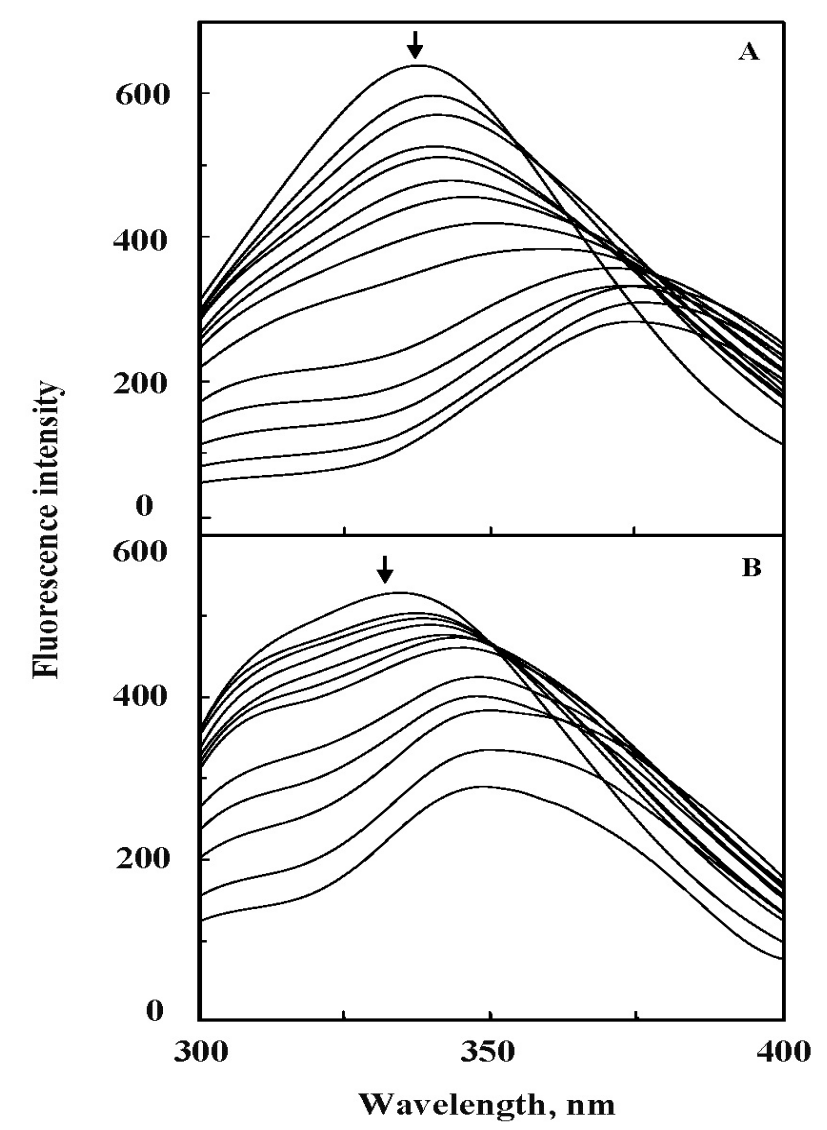

Figure 1: A- Fluorescence spectra of HSA $(1.0 \mu \mathrm{M})$ in the absence and presence of increasing warfarin concentrations

(from top to bottom: 0.0, 1.0, 1.3, 1.6, 2.0, 2.5, 3.0, 4.0, 5.0, $10.0,15.0,20.0,30.0$ and $40.0 \mu \mathrm{M}$, respectively) in $0.06 \mathrm{M}$ sodium phosphate buffer, $\mathrm{pH} 7.4$ at $25^{\circ} \mathrm{C}$ incubated for $60 \mathrm{~min}$, upon excitation at $280 \mathrm{~nm}$. B - Fluorescence spectra of HSA obtained under similar conditions as described in (A) but in the presence of $5.3 \mathrm{M}$ urea. Warfarin concentrations from top to bottom were: $0.0,1.0,1.3,1.6,3.0,4.0,5.0,10.0,15.0,20.0$, 30.0 and $40.0 \mu \mathrm{M}$, respectively.

farin concentrations were indicative of warfarin binding to HSA. Furthermore, drug binding to HSA involved the participation of both Tyr and Trp residues. Since the lone tryptophan residue (Trp 214) and majority of tyrosine residues (14 out of 18 Tyr residues) are located in domains $\mathrm{I}$ and $\mathrm{II}^{2}$, it seems that binding of warfarin to HSA changed the microenvironment around these residues. This agreed well with the location of warfarin binding site in domain II, which is Sudlow's site I on HSA. ${ }^{8,9}$ Binding of warfarin to native HSA has been studied earlier using different techniques including fluorescence spectroscopy and our results were found in agreement to those published earlier. ${ }^{16-18,24,25}$

Fluorescence intensity data were transformed into relative fluorescence intensity by taking the fluorescence intensity of native HSA at $339 \mathrm{~nm}$ in the absence of drug as 100 and plotted against warfarin concentration (Figure 2A). There was a sharp decrease in the fluorescence intensity at lower drug concentrations $(1-5 \mu \mathrm{M})$ which sloped off at higher drug concentrations $(10-40 \mu \mathrm{M})$. Linear decrease

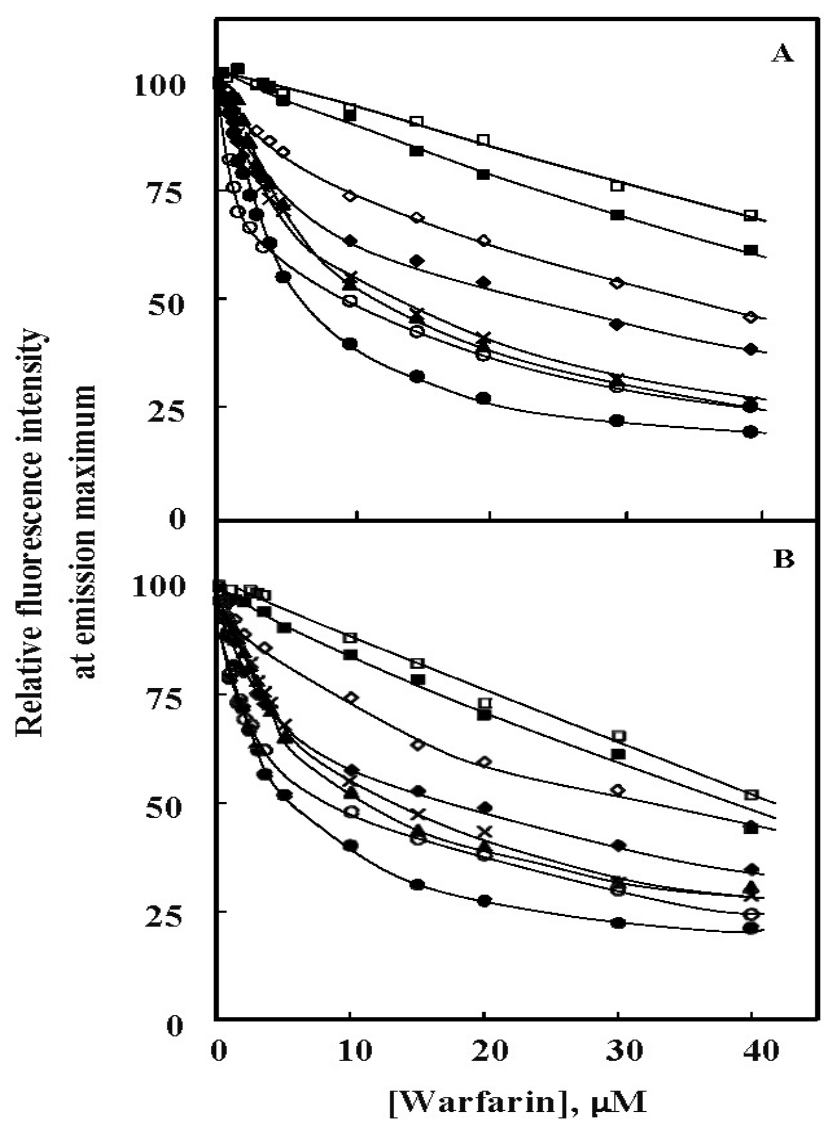

Figure 2: Plots showing change in the relative fluorescence intensity of HSA at the emission maximum with increasing warfarin concentrations, when excited at $280 \mathrm{~nm}$ (A) and 295 $\mathrm{nm}$ (B). Different plots were obtained at different concentrations of urea which were: $\mathbf{0 . 0}(\bullet), 3.0(\circ), 3.5(\Delta), 4.0(\times), 4.5$ $(\diamond), 5.3(\diamond), 6.5(\square)$ and $8.0(\square)$ M.

in the fluorescence intensity at lower drug concentrations and saturation at higher drug concentrations are typical for specific binding of ligands to proteins. ${ }^{26,27}$

Interaction of warfarin with HSA was also studied in the presence of different urea concentrations i.e.: 3.0, 3.5, 4.0, 4.5, 5.3, 6.5 and $8.0 \mathrm{M}$ using fluorescence spectroscopy. Titration of a constant amount of HSA $(1 \mu \mathrm{M})$ was performed with increasing warfarin concentrations $(1.0-40 \mu \mathrm{M})$ in the presence of fixed urea concentration and the resulting fluorescence spectra (upon excitation at $280 \mathrm{~nm}$ ) obtained at $5.3 \mathrm{M}$ urea are shown in Figure 1B. Fluorescence spectra obtained at other urea concentrations are omitted for brevity. Fluorescence spectra obtained in the presence of different urea concentrations were found to be qualitatively similar to those observed in the absence of urea (Figure 1A). However, significant differences in the extent of fluorescence quenching were noticed at different urea concentrations. Fluorescence data were transformed into relative fluorescence intensity in the same way as described above. A comparison of these plots obtained at different urea concentrations showed a significant decrease in the extent of fluorescence quenching (Figure 2A) with the increase in urea 


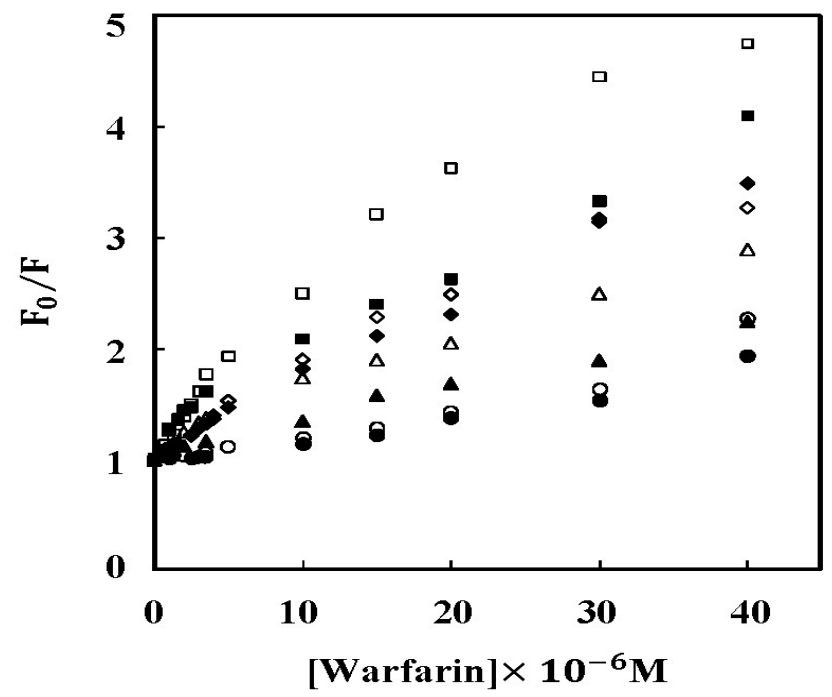

Figure 3: Stern-Volmer plots for tryptophan fluorescence quenching of HSA at increasing warfarin concentrations in the absence and the presence of different urea concentrations; $0.0(\square), 3.0(\square), 3.5(\diamond), 4.0(\triangleleft), 4.5(\Delta), 5.3(\Delta), 6.5(\circ)$ and $8.0(\bullet) \mathrm{M}$. Values of $F_{0}$ and $F$ were taken from Figure 2B.

Table 1: Values of the Stern-Volmer constant $\left(K_{\text {sv }}\right)$ for tryptophan fluorescence quenching of HSA and binding constant $\left(K_{b}\right)$ for the warfarin-HSA complex in the absence and presence of different urea concentrations.

\begin{tabular}{|c|c|c|}
\hline $\begin{array}{c}{[\text { Urea] }} \\
{[\mathrm{M}]}\end{array}$ & $\begin{array}{c}\boldsymbol{K}_{\text {sV }} \\
{\left[\mathbf{M}^{-1}\right]}\end{array}$ & $\begin{array}{c}\boldsymbol{K}_{b} \\
{\left[\mathbf{M}^{-1}\right]}\end{array}$ \\
\hline $\mathbf{0 . 0}$ & $2.17 \times 10^{5}$ & $2.1 \times 10^{5}$ \\
\hline $\mathbf{3 . 0}$ & $1.39 \times 10^{5}$ & - \\
\hline $\mathbf{3 . 5}$ & $1.06 \times 10^{5}$ & $1.7 \times 10^{5}$ \\
\hline $\mathbf{4 . 0}$ & $9.03 \times 10^{4}$ & $1.4 \times 10^{5}$ \\
\hline $\mathbf{4 . 5}$ & $1.09 \times 10^{5}$ & $1.1 \times 10^{4}$ \\
\hline $\mathbf{5 . 3}$ & $6.39 \times 10^{4}$ & $4.7 \times 10^{3}$ \\
\hline $\mathbf{6 . 5}$ & $1.88 \times 10^{4}$ & \\
\hline $\mathbf{8 . 0}$ & $5.34 \times 10^{3}$ & \\
\hline
\end{tabular}

concentration. The pattern of fluorescence quenching with increasing warfarin concentrations remained the same up to $5.3 \mathrm{M}$ urea concentration, showing a marked decrease in the fluorescence intensity at lower drug concentration drug concentrations followed by a smaller decrease at higher drug concentrations. However, at higher urea concentrations $(>5.3 \mathrm{M})$, a linear decrease in the fluorescence intensity was noticed throughout the drug concentration range (Figure 2A). Plots of relative fluorescence intensity versus drug concentration obtained in the presence of 3.0, 3.5 and 4.0 M urea concentrations showed little variation, among each other but were found significantly different from the one, obtained in the absence of urea. There was a progressive decrease in the fluorescence quenching with the increase in urea concentration at each drug concentration as the plots moved upwards on the $\mathrm{Y}$-axis and became linear at higher

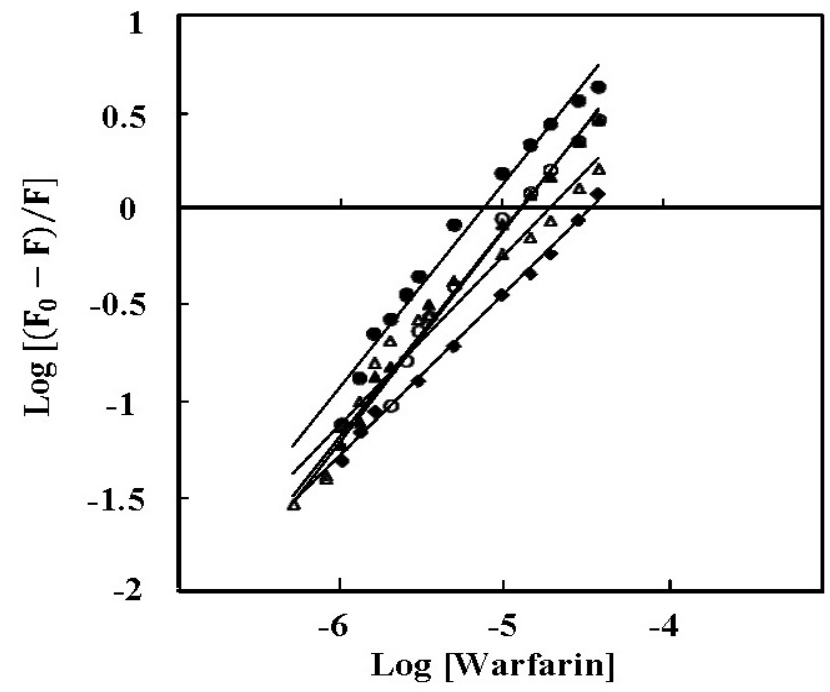

Figure 4: Plots of $\log \left[\left(F_{0}-F\right) / F\right]$ versus Log [Warfarin] in the absence and presence of different urea concentrations. Values of $F_{o}$ and $F$ were taken from Fig. 2A. Different urea concentrations used were: $0.0(\bullet), 3.5(\circ), 4.0(\Delta), 4.5(\Delta)$ and $5.3(\bullet) \mathrm{M}$ urea.

urea concentrations (Figure 2A). Since the decrease in the fluorescence intensity (fluorescence quenching) with increasing warfarin concentrations was suggestive of warfarin binding to HSA, any decrease in the fluorescence quenching in the presence of urea indicated loss in the drug binding to the protein. A significant loss in drug binding was noticed in the presence of $\geq 6.5 \mathrm{M}$ urea due to lesser degree of quenching throughout the drug concentration range. At the highest drug concentration $(40 \mu \mathrm{M})$, about $39 \%$ and $31 \%$ quenching were noticed in the presence of $6.5 \mathrm{M}$ and $8.0 \mathrm{M}$ urea, respectively against $80 \%$ quenching observed with native HSA (Figure $2 \mathrm{~A}$ ). Since the start and the end points of the urea denaturation curve of HSA under these conditions were $3 \mathrm{M}$ and $6.5 \mathrm{M}$ with the accumulation of an intermediate around 5.2 $\mathrm{M}$ urea (Figure omitted for brevity), it appears that warfarin binding to the intermediate was significantly lesser.

To validate these findings, fluorescence spectra were also recorded under similar conditions but upon excitation at $295 \mathrm{~nm}$ (spectra not shown). Presence of urea in the incubation mixture produced significant decrease in the fluorescence quenching (Figure 2B). Although these results were found similar to those obtained with $280 \mathrm{~nm}$ excitation at lower drug concentrations, smaller differences were noticed at higher drug concentrations (Figure 2). For example, at $40 \mu \mathrm{M}$ drug concentration, about $31 \%$ and $48 \%$ quenching in the fluorescence intensity were noticed in the presence of $8.0 \mathrm{M}$ urea, when monitored upon excitation at 280 and $295 \mathrm{~nm}$, respectively (Figures. 2A and B).

Presence of urea decreased the binding of warfarin to HSA as revealed by the decrease in the fluorescence 
quenching, observed in the presence of urea (Figure 2). Drug binding data were analyzed according to the method suggested by Eftink and Ghiron ${ }^{20}$ and the resulting Stern-Volmer plots for warfarin-HSA interaction both in the absence and the presence of different urea concentrations are shown in Figure 3. As can be seen from the figure, plots showed linearity at lower drug concentrations while a significant deviation from linearity was noticed at higher drug concentrations. Values of the quenching constant $\left(K_{s s}\right)$ as determined from the slope of the initial linear parts of the plots are given in Table 1. A value of $K_{s v}\left(2.17 \times 10^{5} \mathrm{M}^{-1}\right)$ was obtained for warfarin-HSA interaction, which was similar to those reported earlier for other drugs, known to bind to site I of HSA. ${ }^{28,29}$ Warfarin is known to bind to site I of HSA molecule. ${ }^{8,9}$ There was a significant decrease in the $K_{s v}$ value with increasing urea concentrations (Table 1), which suggested the increase in the distance between excited fluorophore (Trp) and the ligand (warfarin), due to significant loss in the tertiary structure of the protein at higher urea concentrations. This was in agreement with urea denaturation results, suggesting complete denaturation at higher $(>6.0 \mathrm{M})$ urea concentrations. ${ }^{27}$

Warfarin binding data were also analyzed following published procedure ${ }^{21}$ and the values of the apparent binding constant, $K_{b}$ for warfarin-HSA interaction were determined from the plots shown in Figure. 4. Value of the binding constant, $2.1 \times 10^{5} \mathrm{M}^{-1}$ (Table 1), as obtained in this study was found similar to the one reported ear-

\section{REFERENCES}

1. Kragh-Hansen $U$. Structure and ligand binding properties of human serum albumin. Dan Med Bull. 1990; 37(1): 57-84.

2. Peters T Jr. All about Albumin. Biochemistry, Genetics and Medical Applications. New York: Academic Press Inc.; 1996. 9-75.

3. Sudlow G, Birkett DJ, Wade DN. The characterization of two specific drug binding sites on human serum albumin. Mol Pharmacol. 1975; 11(6): 824-32.

4. Peterson CE, Kwaan HC. Current concepts of warfarin therapy. Arch Intern Med. 1986; 146(3): 581-4.

5. Petersen P, Boysen G, Godtfredsen J, Andersen ED, Andersen B. Placebocontrolled, randomised trial of warfarin and aspirin for prevention of thrombo embolic complications in chronic atrial fibrillation. The Copenhagen AFASAK study. Lancet 1989; 333(8361): 175-9.

6. Mok CK, Boey J, Wang R, Chan TK, Cheung KL, Lee PK, et al. Warfarin versus dipyridamole-aspirin and pentoxifylline-aspirin for the prevention of prosthetic heart valve thromboembolism: a prospective randomized clinical trial. Circulation 1985; 72(5): 1059-63.

7. Holford NHG, Benet LZ. Pharmacokinetics and pharmaco dynamics: Dose selection and the time course of drug action. In: Katzung BG. (ed.), Basic and Clinical Pharmacology (7th ed.). Stamford, CT; Appleton and Lange; 1998. 34-49.

8. Petitpas I, Bhattacharya AA, Twine S, East M, Curry S. Crystal structure analysis of warfarin binding to human serum albumin: anatomy of drug site I. J Biol Chem. 2001; 276(25): 22804-9.

9. Fehske KJ, Schläfer U, Wollert U, Muller WE. Characterization of an important drug binding area on human serum albumin including the high-affinity binding sites of warfarin and azapropazone. Mol Pharmacol. 1982; 21(2): 387-93.

10. Sjöholm I, Ekman B, Kober A, Ljungstedt-Påhlman I, Seiving B, Sjödin T. Binding of drugs to human serum albumin: XI. The specificity of three binding lier. ${ }^{16,30}$ The binding constant decreased from $2.1 \times 10^{5} \mathrm{M}^{-1}$ under native conditions to $4.7 \times 10^{3} \mathrm{M}^{-1}$ in the presence of $5.3 \mathrm{M}$ urea (Table 1). Although, there was a decrease in both Stern-Volmer constant $\left(K_{s y}\right)$ and apparent binding constant $\left(K_{b}\right)$ with increasing urea concentrations, it was more pronounced in $K_{b}$ at higher urea concentrations (e.g. $5.3 \mathrm{M}$ ).

\section{CONCLUSION}

These results suggested the sensitivity of warfarin binding site to urea as alteration in the three-dimensional structure of defatted HSA markedly affected its drug binding ability. In view of the structural stabilization offered by bound fatty acids in fatted HSA, ${ }^{31}$ such effects of urea may not be as pronounced as observed with defatted HSA.

\section{CONFLICT OF INTEREST}

The authors declare that there is no conflict.

\section{ACKNOWLEDGEMENT}

Financial support from the University of Malaya in the form of Post Graduate Research Grant (PPPP0100/2010B) to N.S. is gratefully acknowledged. We thank the Dean, Faculty of Science and the Head, Institute of Biological Sciences, University of Malaya for providing all necessary facilities. sites as studied with albumin immobilized in micro particles. Mol Pharmacol. 1979; 16(3): 767-77

11. Oida T. Proton nuclear magnetic resonance study on the multimode interactions of human serum albumin with drug molecules. J Biochem. 1986; 100(1): 99-113.

12. Feroz SR, Mohamad SB, Bujang N, Malek SNA, Tayyab S. Multi spectroscopic and molecular modeling approach to investigate the interaction of flavokawain B with human serum albumin. J Agric Food Chem. 2012; 60(23): 5899-908.

13. Dill KA, Shortle D. Denatured states of proteins. Annu Rev Biochem. 1991; 60(1): 795-825.

14. Ivanov AI, Korolenko EA, Korolik EV, Firsov SP, Zhbankov RG, Marchewka MK, et al. Chronic liver and renal diseases differently affect structure of human serum albumin. Arch Biochem Biophys. 2002; 408(1): 69-77.

15. Zatón AM, Ochoa de Aspuru E. Horseradish peroxidase inhibition by thiouracils. FEBS Lett. 1995; 374(2): 192-4.

16. Wilting J, van der Giesen WF, Janssen LH, Weideman MM, Otagiri M, Perrin $\mathrm{JH}$. The effect of albumin conformation on the binding of warfarin to human serum albumin. The dependence of the binding of warfarin to human serum albumin on the hydrogen, calcium, and chloride ion concentrations as studied by circular dichroism, fluorescence, and equilibrium dialysis. J Biol Chem. 1980; 255(7): 3032-7.

17. Larsen FG, Larsen CG, Jakobsen P, Brodersen R. Interaction of warfarin with human serum albumin. A stoichiometric description. Mol Pharmacol. 1985; 27(2): 263-70.

18. Vorum H, Fisker K, Brodersen R. High-affinity binding of two molecules of warfarin and phenprocoumon to human serum albumin. Biochim Biophys Acta. 1994; 1205(2): 178-82. 
19. Pace CN, Shirley BA, Thomson JA. Measuring the conformational stability of a protein. In: Creighton TE (ed.), Protein Structure: A Practical Approach. Oxford: IRL Press; 1989. 311-30.

20. Eftink MR, Ghiron CA. Fluorescence quenching studies with proteins. Anal Biochem. 1981; 114(2): 199-227.

21. Min J, Meng-Xia X, Dong Z, Yuan L, Xiao-Yu L, Xing C. Spectroscopic studies on the interaction of cinnamic acid and its hydroxyl derivatives with human serum albumin. J Mol Struct. 2004; 692(1): 71-80.

22. Muzammil S, Kumar Y, Tayyab S. Anion-induced stabilization of human serum albumin prevents the formation of intermediate during urea denaturation. Proteins 2000; 40(1): 29-38.

23. Kumar Y, Tayyab S, Muzammil S. Molten-globule like partially folded states of human serum albumin induced by fluoro and alkyl alcohols at low $\mathrm{pH}$. Arch Biochem Biophys. 2004; 426(1): 3-10.

24. Parikh $\mathrm{HH}$, McElwain K, Balasubramanian V, Leung W, Wong D, Morris $\mathrm{ME}$, et al. A rapid spectro fluorimetric technique for determining drug-serum protein binding suitable for high-throughput screening. Pharma Res. 2000; 17(5): 632-7.

25. Rich RL, Day YS, Morton TA, Myszka DG. High-resolution and highthroughput protocols for measuring drug/human serum albumin interactions using BIACORE. Anal Bio chem. 2001; 296(2): 197-207.
26. Tayyab S, Sharma N, Khan MM. Use of domain specific ligands to study urea-induced unfolding of bovine serum albumin. Biochem Biophys Res Commun. 2000; 277(1): 83-8.

27. Rownicka-Zubik J, Sulkowska A, Gazdzicka K, Bojko K, Maciazek-Jurczyk M, Pozycka J, et al. Fluoroscence analysis of sulfasalazine bound to defatted serum albumin in the presence of denaturing factors. J Mol Struct. 2009; 924-6 : 371-7.

28. Wang G, Li X, Ding X, Wang D, Yan C, Lu Y. Exploring the mechanism of interaction between 5-(ethoxycarbonyl)-6-methyl-4-(4-methoxyphenyl)3,4-dihydropyrimidin-2(1H)-one and human serum albumin: spectroscopic, calorimetric and molecular modeling studies. J Pharma Biomed Anal. 2011; 55(5): 1223-6.

29. Abdollahpour N, Asoodeh A, Saberi MR, Chamani J. Separate and simultaneous binding effects of aspirin and amlodipine to human serum albumin based on fluorescence spectroscopic and molecular modelling characterizations: a mechanistic insight for determining usage drugs doses. J Lumin. 2011; 131(9): 1885-99.

30. Fleury F, lanoul A, Berjot M, Feofanov A, Alix AJ, Nabiev I. Camptothecinbinding site in human serum albumin and protein transformations induced by drug binding. FEBS Lett. 1997; 411(2): 215-20.

31. Ahmad N, Qasim MA. Fatty acid binding to bovine serum albumin prevents formation of intermediate during denaturation. Eur J Biochem. 1995; 227(12): 563-5. 